\title{
Metacognition Training in the Chinese University Classroom: an action research study
}

HUANG (family name) Jing

Zhanjiang Teachers University / The University of Hong Kong, China

ABSTRACT In the author's previous teaching English as a foreign language (TEFL) experience, he had found that Chinese university students were overdependent on teachers in EFL learning. Drawing on research on language learning strategies, he used metacognition training (MT) as a form of classroom intervention to promote learner autonomy. This article reports on an action research study of MT integrated in two TEFL courses (EFL Reading and Language Teaching Methodology) at a Chinese teachers' university. The aim of the study was to gain a better understanding of the professional context through exploring students' views towards the impact of MT on EFL learning. Both quantitative and qualitative data were collected by means of questionnaires, and the results from the study of the first course were used to introduce improvements in the second. It was found that students generally held positive views towards MT incorporated into the regular EFL curriculum. The study has also identified concerns that merit further explorations and areas of MT that need amendment, e.g. learner resistance to MT, and learning journals as a reflective learning tool.

Keywords: language learning strategies; learner autonomy; metacognitive knowledge; metacognition training; English as a foreign language learning

\section{Introduction}

This action research study grew out of my dissatisfaction with Chinese university students' over-dependence on teachers in EFL learning and my sustained efforts to promote learner autonomy ${ }^{1}$ through metacognition training (MT). Participants in the study were English majors in a four-year BA TEFL (teaching English as a foreign language) degree programme at Zhanjiang Teachers university, Guangdong, China. These students were actually pre-service student teachers because they would become English teachers in primary or secondary schools after graduation. In the first two years, they were offered proficiency courses (listening, speaking, reading and writing,

\footnotetext{
${ }^{1}$ Learner autonomy can be defined as ‘the capacity to take control of one’s own learning' (Benson, 2001, p. 47).
} 
etc.) while from the third year language-methodology and other theoretical-oriented courses were added to their curriculum.

In this paper, I shall critically examine and reflect on the possibilities and conditions of MT incorporated into the EFL regular curriculum in the promotion of learner autonomy. I shall first explain the concepts of metacognition and MT, and their importance in EFL learning in the Mainland Chinese context. Then I shall briefly describe the context of MT and the methodology of the action research. The major part of the paper, however, focuses on: the detailed procedures of two MT projects integrated in the regular EFL curriculum (first, the second-year EFL Reading, then, the third-year Language Teaching Methodology) for the same batch of students, a follow-up evaluation of each MT project from students’ perspectives, and finally the overall reflections on the two classroom interventions from a critical point of view.

\section{Metacognition and MT in EFL Learning}

The term 'metacognition' used in this study is conceptualized as a broad notion consisting of two separate and distinct components - metacognitive strategies and metacognitive knowledge (Wenden, 1998). Metacognitive strategies are 'higher order executive skills that may entail planning for, monitoring, or evaluating the success of a learning activity’ (O’Malley \& Chamot, 1990, p. 44). Metacognitive knowledge can be glossed as 'the stable, statable and sometimes fallible knowledge learners acquire about themselves as learners and the learning process' (Wenden, 1995, p. 185). According to O’Malley \& Chamot (1990), language learning strategies (LLS) can be 
classified into three categories, namely metacognitive strategies, cognitive strategies, and social/affective strategies ${ }^{2}$. I find this classification useful and relevant to this study because the three-way distinction reveals the internal hierarchical relationship between different categories of learning strategies and emphasizes the role of metacognitive strategies in language learning.

Stimulated by Rubin (1975) and Stern (1975), extensive research into LLS has been conducted to investigate good and poor second/foreign language learner behaviours. Although this body of research has not generated unanimous agreement on what good language learners are in terms of ideal strategy use, researchers have generally found that good language learners are those who are metacognitively aware of their language learning processes and use metacognitive, cognitive and social/affective strategies flexibly and effectively (e.g. Ellis, 1994; Cohen, 1998). Wenden (1998) emphasizes the role of metacognitive knowledge as a prerequisite for self-regulation, which is considered as essential to learner autonomy, because 'it informs planning decisions taken at the outset of learning and the monitoring processes that regulate the completion of a learning task...and decisions to remediate; it also provides the criteria for evaluation made once a learning task is completed' (p. 528).

Although metacognition plays an important role in language learning, only recently has classroom-based research begun to focus on various dimensions of Mainland Chinese learners' metacognitive knowledge and strategies in EFL learning

\footnotetext{
${ }^{2}$ According to O’Malley \& Chamot (1990), cognitive strategies 'operate directly on incoming information, manipulating it in ways that enhance learning' (p. 44), while social/affective strategies 'represent a broad grouping that involves either interaction with another person or ideational control over affect' (p. 45).
} 
(see Zhang, 2003, for a review). According to a state-of-the-art review by McDonough (1999), overall LLS are generally teachable through learner/strategy training. It has also been argued that learner training (especially MT, which usually aims at raising conscious awareness of three main strategies in EFL learning, i.e. planning, monitoring and evaluating) can enhance language learning and learner autonomy (e.g. Wenden, 1991; Dickinson, 1992; Cohen, 1998; Hedge, 2000) ${ }^{3}$. However, there has so far been insufficient empirical research into the effect of learner training of any kind on Chinese EFL learning at the primary, secondary and tertiary levels. In particular, little research has been undertaken to investigate the impact of MT on EFL learning in the Mainland Chinese context. This paper reports on an action research study, which set out to investigate the impact of MT through exploring the broad question: 'What are students' views towards MT integrated in the regular EFL curriculum?’

\section{Context of MT}

Although the research background and the theoretical insights outlined above constitute a strong justification for MT, MT in this action research study was first motivated by two factors in my teaching experience: university students' disproportionate dependence on teachers for prescribing 'best' methods and their lack of confidence and autonomy in EFL learning. For instance, in and out of the classroom and in email exchanges, students often raised such concerns:

\footnotetext{
${ }^{3}$ Note that some researchers (e.g. Rees-Miller, 1993; Benson, 1995; Schmenk, 2005) have questioned the contribution of learner training to language learning.
} 
Mr. Huang, what is the best method of learning English (or improving reading, listening, speaking and writing)?

I have adopted the teacher's advice, but I have made no progress.

I have not learned any real things in class. I always get low marks.

All these pointed to the fact that many of our learners were not reflective learners. They were not metacognitively aware of their learning processes (or outcomes) and were not able to take control of their learning (not autonomous learners). As reading was a convenient way of heightening metacognitive awareness (knowledge) in an acquisition-poor EFL environment, I initiated my first classroom intervention by incorporating MT into a regular EFL Reading curriculum for the second-year English majors in three classes (around 38 in each class) for a full semester from September 2000 to January 2001 (18 teaching weeks). However, in evaluating the impact of the pedagogical intervention, I found both positive and negative views held by students towards the MT project. In order to further pursue the notion of MT for metacognitive knowledge and learner autonomy, a four-week MT curriculum package was integrated into the Language Teaching Methodology course during September 2001-January 2002 for the same batch of student teachers who were then in their third year.

In both MT projects, I chose to integrate MT into the normal curriculum out of the following concerns:

- In our examination-oriented EFL context, an integration of MT into the normal 
curriculum would reduce resistance and increase chances of success. Especially at the time of MT in EFL Reading, students were preoccupied with the preparation of TEM-4 $4^{4}$. If we kept class time for MT within a certain limit, MT would appear more 'meaningful' to students and would be better regarded by our stakeholders (students, teachers and the administration).

- Empirical findings and theoretical insights tend to support the integration of learner training into the regular curriculum (e.g. Sinclair \& Ellis, 1992; Cohen, 1998).

In incorporating MT into the two TEFL courses, I assumed that learner autonomy could be fostered through enhancing learners' metacognitive knowledge of the EFL learning process (I return to this assumption in the course of the article).

\section{Methodology of Action Research}

The action research study was grounded in my understanding of the above two contexts - the research context (theoretical insights that MT drew on) and the classroom context of MT. The self-reflective enquiry constituted a complete single action research cycle, which was triggered by the identification of a problem (students' over-dependence on teachers) in my own classroom, followed by a series of interrelated enquiries and actions, such as:

\footnotetext{
${ }^{4}$ TEM-4 (Test for English Majors, Band 4) is a national proficiency test that English majors in Chinese universities are supposed to pass by the end of their second year in the four-year BA degree programme. Some universities, e.g. the college where the MT was conducted, make TEM-4 a prerequisite for the conferment of the BA degree.
} 
- An initial, yet theoretically informed classroom intervention (MT in EFL Reading);

- A follow-up participant evaluation leading to a better understanding of the situation;

- A second classroom intervention (MT curriculum package in Language Teaching Methodology);

- A second self-evaluation; and finally,

- Critical reflections on the data and the generation of new insights.

The study drew on multiple data: questionnaires administered to students (Appendices 1-2), students' course journals, and participant observation of and informal interviews with students. Although there was room for improvement for the questionnaire design (e.g. item wording) in both MT projects, the use of closed items in both questionnaires allowed me to elicit large amounts of useful information economically. In addition, questionnaire data was triangulated by rich qualitative data. In what follows, I shall first provide an account of each MT project so that I can discuss their respective impact on EFL learning through exploring students’ perspectives.

\section{MT in EFL Reading}

Time constraints did not allow us to deal with a wide range of specific reading strategies and cognitive strategies in general EFL learning because we had to follow the EFL reading curriculum and to cover the main content of the reading textbook. On 
the other hand, I found that EFL students at this stage still lacked the ability to plan, monitor and evaluate their reading processes. Therefore, I decided to give more attention to promote EFL readers' metacognitive knowledge of EFL reading and to provide them with opportunities to familiarize themselves with some basic metacognitive strategies, such as general techniques in planning, monitoring and evaluating their reading. We gave special emphasis on comprehension monitoring the evaluating of the success or failure of the meaning-making process and the regulating of strategies to remedy comprehension problems (Irwin, 1991) - which is regarded as one of the most important aspects of metacognitive control and an essential strategy in general reading comprehension (Block, 1992; Casanave, 1988).

\section{Procedures of MT in EFL Reading}

The construct of MT was operationalized through the following five broad procedures which were evaluated in the questionnaire (Appendix 1). The 'Process Approach' procedure below covered three sub-procedures, corresponding to relevant questionnaire items in Appendix 1.

\section{Selecting Teaching Materials}

The designated textbook (Wang \& Yao, 1996) was strategy-embedded, made up of 18 thematic units, and grouped under 3 broad reading skills - skimming, scanning and drawing inferences. Articles of various topics and genres from other sources were also brought to class for supplementary reading on a regular basis, and students were 
required to do a certain amount of out-of-class reading to write reading reports (summary and critique of what they had read). Two book chapters, 'Overview of Comprehension Process Teaching' and 'Teaching Metacognitive Process' were selected from Irwin (1991) to provide students with a background of reading processes. The two chapters were used as materials for four mini-lectures (15 minutes each), which were inserted consecutively into four regular class sessions (50 minutes each) in the first four weeks of the reading course for initial explicit teaching of reading comprehension processes.

\section{Adopting a Process Approach in Teaching Reading Comprehension}

In the Chinese university classroom, the prevailing product approach to teaching EFL reading had failed to make readers become conscious of their reading strategies. Therefore, in my reading class, reading processing was emphasized rather than correct answers to questions. Usually, if students were doing well, examining their reading processes/strategies through whole-class discussion could give them an insight into the successful strategies they used. This information could help them become more aware of their repertoire of strategies. More importantly, in a classroom instruction environment, sharing information in a small group by means of reflection could help them increase their strategy awareness and expand their strategy use. When students had read a passage and completed the comprehension exercises for that passage, I often tried to focus their attention on reading processes by asking them to recall how they had got their answers. If the answer was not correct, looking at the process by 
which students had come up with the response could help identify where thinking might have gone astray. In summary, the process approach was able to provide a useful framework for the accommodation of MT into the regular reading course, which was characterized in the classroom by the following main procedures: (a) the whole class discussed successful reading strategies used by different students, (b) students reflected on reading processes (shared information about reading) in a group, and (c) the teacher helped students analyze how they had arrived at a correct/wrong answer by means of asking them to recall their processes in understanding a certain question (see, respectively, Items 1, 5, 6 in Appendix 1).

\section{Explicit Instruction of Comprehension Monitoring}

Explicit instruction was first integrated into the background-providing mini-lectures, especially by using the chapter on metacognitive processing by Irwin (1991). Another procedure was to provide students with paragraphs in which the information was inconsistent and then to ask a series of questions which could turn on their monitoring processes (ibid). However, in our context, explicit instruction was kept to a certain limit so that it would not be seen as 'interfering' too much with the regular curriculum.

Incidental Teaching of Comprehension Monitoring and Think-alouds

Whenever students did not understand what they were reading, I would encourage them to clarify the source of the breakdown, or I would use concrete examples in the 
teaching materials to demonstrate what actions they could take to remedy the situation. From time to time, I used think-aloud techniques to model the behaviour of myself as a relatively competent reader, in order that students' strategic resources ('strategy schemata', in Casanave's term, 1988) for the most part being in a dormant state could be awakened to some extent, and might be expanded by comparing and evaluating the monitoring processes between peers and among groups.

\section{Reading Diaries}

Besides writing reading reports on reading content, students were asked to keep a reading journal to record their conceptualization of reading and reflections on the failure and success of their reading processing, their efforts to clarify ideas, and their solutions to problems. Students were provided with simple guidelines, exemplified by diary extracts quoted in Goh’s (1997) investigation into metacognitive awareness of Chinese ESL learners (listeners) enrolled in an intensive ESL programme in the National Institute of Education, Singapore. A combination of reading reports and reading diaries, assessed in terms of both quantity and quality, constituted $20 \%$ of the final grade. By quality, I meant true reflection instead of good composition in the case of reading diaries.

\section{Students' Views towards MT in EFL Reading}

\section{Questionnaire Findings}

In the last teaching week of the reading course, a questionnaire made up of closed 
items presented on a 1-5 Likert Scale was administered to all the students involved to investigate their perceptions of the impact of MT (N=92, see Appendix 1). Analysis of the questionnaire indicated that students held positive views towards five out of six classroom procedures:

- Whole-class discussion about successful reading strategies (Item $1=68 \%$ );

- Explicit instruction of reading processes (Item 2 = 70\%);

- Incidental teaching of reading processes (Item 3 = 83\%);

- $\quad$ Keeping a regular reading diary (Item 4 = 59\%);

- Reflecting on one’s own reading processes in a group (Item $5=83 \%$ ); and,

- Analysis of reading strategies by recalling actual reading processes (Item $6=$ $79 \%)$.

However, $70 \%$ of students stated that they were not interested in writing reading diaries (Item7A). This seemed congruent with the relatively low rating for Item 4. (Unfortunately, there was no item in the questionnaire investigating learners' attitudes towards reading-report writing.) This finding confirmed my observation that many students were not interested in writing reading/learning journals.

\section{Reading Diaries and Informal Interviews}

As shown above, students in the EFL reading course were asked to write reading reports on the reading content, and to keep learning journals to record their reflections 
on EFL reading processing. Although I emphasized learning journals as a learning tool (Matsumoto, 1996; Goh, 1997) and encouraged them to comment on the classroom MT practice throughout the reading course, students wrote much more in reading reports than in journals and seldom evaluated the effectiveness of the ongoing MT project in their learning journals. Besides, in their journals, some students made positive comments on reading-report-writing, which was not originally conceptualized as a way to promote metacognitive awareness or learner autonomy.

By conducting content analysis of learners' diaries, I found that the entries did not match my previous expectations and requirements: students did not report their metacognitive knowledge and processes of reading to the extent that I had expected. Instead, they focused more on difficulties and constraints in EFL learning and their responses to them. By conducting informal interviews with a group of students towards the end of the MT project, I began to realize that their reluctance to self-report their metacognitive processing in EFL reading might result from their lack of metacognitive knowledge to talk about their learning. This reluctance, however, could also be interpreted as silent resistance to the incorporated MT project because I had made it clear that they could write about their reading processing in Chinese if they found it difficult to express the complicated thoughts in English. Of course, English majors might reject the idea of writing Chinese because this did not seem to directly help their English learning. Based on my interviews with several other groups of students and my participant observation in the course of MT, some students were not comfortable with taking on a 'metacognitive', 'reflective' role from the very 
beginning of the MT programme. That might explain why on various occasions, students often made comments like 'reflect what' and 'why reflect'. This kind of resistance seemed to be reflected in the relatively low rating given to journal-writing as a tool to raise metacognitive knowledge of learning (Item $4=59 \%$ ). In contrast, the main reasons for producing more reading reports were that they found reading-report-writing to be more useful in enhancing word power, grammar, reading and writing. Improvement in these skills would be more relevant to their immediate concerns, e.g. the influential TEM-4 in the coming semester.

Students' differentiated attitudes towards reading-report writing and reflective journal-keeping, together with their conceptualizations of the role of reflection in learning (e.g. 'reflect what' and 'why reflect'), made me realize that students had doubts about whether reflective learning activities were beneficial to their learning. Students' doubts might be interpreted on the grounds that reflection (e.g. reflective journal-keeping) usually took time to generate visible results in language learning. From their perspectives, tangible language achievement was particularly important in an examination-oriented context where conferment of the BA degree was related to passing a big examination like TEM-4. Therefore, journal-keeping which aimed at enhancing reflection on learning was probably taken as an added external force (burden) to compete for students' valuable time and was thus resisted. This gave me the feeling that for a MT programme to succeed in an examination-oriented context, programme design and implementation should take into account students' learning expectations and learning goals. 
Before I initiated MT in EFL Reading, I assumed that learner autonomy could be enhanced by raising metacognitive knowledge (through MT). This remained an assumption. However, as a teacher-researcher, I felt encouraged by students' generally positive views towards MT incorporated into the regular curriculum (as shown in the questionnaire responses). Given the complexities of students' views towards MT in EFL Reading and the insights I drew from reviewing the literature on metacognition, I decided to carry on the sort of MT work to further explore the possible impact of MT on EFL learning from students’ perspectives, although I was aware that I might not be able to measure directly to what extent students' autonomy in learning would be enhanced when a learning programme ended. Another reason for me to continue MT in the EFL classroom was that, in the initial MT project, I felt that I had emphasized metacognitive awareness too much to the neglect of cognitive and social/affective strategies (which students might find more useful in their learning). That is to say, in the MT that followed, I would give more attention to cognitive and social/affective strategies to see if students' attitudes towards MT would undergo any change. Taking all these into consideration, I had intended to update MT with another batch of students in EFL Reading in order to further examine students' attitudes towards the notion of metacognition in EFL learning. However, as the EFL Reading course was given to another teacher and I was assigned to teach another course, Language Teaching Methodology, to the same batch of students who were then in their third year, I thought that I could incorporate MT into a different course at a different time to see whether MT would be better received one year later (especially when the students had 
already taken TEM-4 in their second year and thus had much less examination pressure).

\section{MT Curriculum Package}

The second MT project was incorporated as a four-week (2 hours per week) component into the Language Teaching Methodology (LTM) course. For various reasons, the LLS component had been previously excluded from the LTM curriculum in our context. My decision to integrate MT package into LTM and to make it metacognition-oriented, was also motivated by the following concerns: (1) feedback from student teachers of previous batches indicated that the LTM course in the past had not provided them with a framework to guide their own pupils to learn, (2) senior students still felt a need to learn how to learn and to better their English even though they had reached a stage of learning how to teach, and (3) a component of language learning strategies has recently been included for the first time in the new five-component curriculum criteria for EFL teaching in Chinese primary and secondary schools (see China Ministry of Education, 2001), and therefore student teachers who would become primary or secondary English teachers about one year later should first familiarize themselves with LLS.

\section{Procedures of the MT Curriculum Package}

The second MT project was restructured in terms of training content, resulting in considerable attention being given to cognitive and social/affective strategies, in 
addition to a primary focus on metacognition. This was to reflect an assumption made in the initial MT project: if the EFL readers had been provided with sufficient opportunities to practise cognitive and social/affective (reading) strategies right before the abstract notion of metacognition was brought in all of a sudden, readers would have benefited more from MT and the observed resistance would have been reduced. The MT curriculum package covered the following topics and procedures:

\section{Explicit Instruction: an overview of LLS and LLS training}

Drawing on a chapter ('How Does the Learner Deal with the Process of Learning?') in Williams \& Burden (1997) and other relevant sources (e.g. Brown, 1994; Wen, 1996; Cohen, 1998), I explored with students: working definitions and common characteristics of LLS; students' existing strategy repertoire, by building on different categories of common strategies discussed in the teaching materials; the notion of 'learning to learn', through reading relevant materials and group discussion based on students' learning experience; studies of good and poor language learners and their implications, using case studies of Chinese EFL learners (e.g. Wen, 1996); different classifications of LLS in the current literature, and the primary role of metacognition (e.g. emphasizing learners' stepping outside their learning and looking at it from outside); and finally, basic procedures of learner training.

\section{Self-evaluation of Strategy Use}

Following the explicit instruction of LLS, students conducted project work for 
self-evaluation of their current and previous learning processes by referring to Oxford's (1990) SILL ('Strategy Inventory for Language Learning,' version for speakers of other languages learning English). I told them that I would expect and value true self-evaluation rather than artificially high self-rating.

\section{Essay-writing on LLS and SILL}

Students were required to submit two essays to pass the LTM course, with one of them being a self-evaluation using SILL as a learning tool. Students were encouraged to reflect on their experience of strategy deployment in EFL learning, by relating their test scores on the six categories of SILL to their past EFL learning experience, and by drawing on the theoretical knowledge of language learning/teaching they acquired from the ongoing LTM course.

\section{Selected Readings}

Selected readings focused on the relationship between metacognition and EFL learning and teacher-learner roles in promoting learner autonomy. Some articles were so impressive and stimulating that most students recorded their reflections in their thinking journals (e.g. Mariani, 1997).

\section{Thinking Journals}

Although $70 \%$ of the students said that they were not interested in journal-writing in the MT project in EFL Reading, they were still asked to keep a journal throughout the 
second MT project and the whole LTM course. The reason was that I wanted to examine whether students' attitudes towards journal-writing would undergo changes in a different situation where the examination pressure was largely reduced. This time the journals were called 'thinking journals', recording perceptions of EFL learning, reflections on the success or failure in strategy deployment, and comments on the MT package. The pedagogical purpose of keeping a journal was the same as that in the EFL Reading MT - to help foster metacognitive knowledge through reflecting on the EFL learning process. I explained that insights from their diaries would help curriculum innovation and future students. Again, to involve students in reflecting on their learning processes, I told them that thinking journals would be taken as a form of continuous assessment and would account for $20 \%$ of the final grade. Journal entries were evaluated both quantitatively and qualitatively. For example, I looked at how frequently learners had recorded their reflections and how well learners had documented their learning processes in the real sense. Although students had gained some experience of keeping a learning journal in my EFL Reading course, they were still provided with some guidelines for journal-writing:

- Thinking journals should focus on the expression of meaning instead of pursuing grammatical correctness in writing, as journals would not be corrected.

- Thinking journals should focus on thinking of and reflecting on the learning process (e.g. commenting on reading materials, classroom methodologies, own deployment of learning strategies, and personal learning experience). 
- Students should not hide what they might consider as 'bad' strategies/habits. Marks were not given to deliberate reporting of 'good' learning behaviours.

\section{Students' Views towards the MT Curriculum Package}

\section{Questionnaire Findings}

A questionnaire consisting of closed and open-ended items was administered to all the students in three classes at the end of the LTM course to assess the overall impact of the package on students' EFL learning, to examine students' attitudes towards integrating the package into the traditional LTM curriculum, and to identify beneficial and ineffective elements of the package ( $\mathrm{N}=109$, see Appendix 2). (This was different from the questionnaire investigation for the initial MT project, which examined students' attitudes towards specific MT procedures.) There were two reasons to administer the questionnaire at the end of the course (rather than the four-week curriculum package). First, in the subsequent weeks following the package, there was still incidental teaching of learning strategies to enhance the overall impact of the package. Second, students would be in a better position to evaluate the integrated MT package at the end of the semester when they had acquired sufficient knowledge about language learning/teaching from the LTM course.

\section{Analyzing the Closed Items of the Questionnaire}

The combined percentages of 'Strongly agree' and 'Agree' for ten (Items 1-4, 7, 9, 11, 13-15) out of the fifteen items indicate a general tendency of positive reaction towards 
the package. Several trends emerged when the positive views were categorized, broadly:

- The necessity of including general strategy training and MT in the LTM course and the usefulness of strategy training and MT in own EFL learning and future teaching (Items 1 = 95\%; 2 = 87\%; 7 = 81\%; $14=90 \% ; 15=67 \%$ ).

- The effectiveness of the MT package in raising conscious awareness of learning processes/strategies (Items $3=76 \% ; 4=82 \%$ ) and in enhancing responsibility for own learning (Item $9=63 \%$ ).

- Useful learning/reflective tools, e.g. thinking journals (Item $11=68 \%$ ) and successful MT procedures, e.g. SILL (Item $13=75 \%$ ).

In contrast, the combined percentages of "Strongly agree" and "Agree” for the items listed below indicate that the MT package was not very effective in these areas. These low ratings, however, were not a surprise to me (except Item 12) when taking into consideration the short time frame of the MT package:

- Effectiveness of MT in terms of enhancing: actual strategy deployment (Item 5 = 54\%); language performance, e.g. the four language skills (Item $6=59 \%$ ); transferability of LLS to non-language subjects (Item $8=49 \%$ ); and, confidence in language learning (Item $10=46 \%$ ).

- Interest in keeping a journal remaining low (Item $12=39 \%$; compare Item 7A = 
$30 \%$ in the first MT in EFL Reading) in spite of a relatively high rating on thinking journals as a learning/reflective tool (Item $11=68 \%$; compare Item $4=$ $59 \%$ in MT in EFL Reading).

\section{Interpreting Open-ended Responses}

In order to reduce the open-ended responses in the questionnaire to manageable proportions, only responses from one randomly selected class $(\mathrm{N}=38)$ were analyzed in detail. Content analysis of explicit mentions by respondents resulted in one dominant theme: the package generally enhanced metacognitive knowledge of language learning processes and strategies, was beneficial to language learning, and would be helpful in the future career as a teacher, and should be included in the LTM curriculum $(\mathrm{N}=35)$. In general, there was a close match of responses between the open-ended part and the closed items. However, the open-ended responses gave us access to some dimensions of the students' attitudes, which were not attainable in the closed part of the questionnaire. For example, some respondents stated that the MT curriculum package was very enlightening (a 'real eye-opener' ${ }^{5}$ ) and should have been launched in their first year in college; some expressed gratitude for my setting up the MT programme; some elaborated on specific effects resulting from the package; and finally, some gave comments on the success or failure of the training procedures: successful procedures comprised self-evaluation with SILL, strategy-use brainstorming given a leaning task, and teacher's comparison of different strategies in

\footnotetext{
${ }^{5}$ This kind of comments indicates that some of the students seemed to forget there was MT in EFL Reading, or that the actual effect of the initial MT was not strong and lasting.
} 
different contexts, whereas ineffective elements included not providing enough examples to illustrate and reinforce strategy use, and using difficult materials in classroom instruction.

\section{Voices Expressed in Thinking Journals}

Content analysis of the thinking journals indicated that the second MT project was beneficial to learning and was welcomed by students. The two extracts below (unedited) by two students were common examples of student perception towards the overall impact of the MT curriculum package:

... I had used learning strategies since I began to learn English in Grade 5 in primary school. At the beginning, it worked, but gradually, my English learning was not so effective. Before I took language methodology course, I didn't know what kind of learning strategies I used and how often I used them. But now, I know some, especially after I answered the questions of Strategy Inventory For Language Learning [SILL] on the worksheet. For example ...

Learning strategies should be an essential part of this course. Since most of us are to-be teachers, our future career is teaching. As teachers, we must know how to learn, then we are able to teach others... Learning strategies also have some effects on my own learning and my attitude to learning. Before I learned these learning strategies, I was seldom aware of my learning process. I did not notice how I was learning. Although I did have many strategies in my learning, I didn't pay much attention to them, and even didn't know they were learning strategies...The learning strategies also improve my language performance, for example, reading and listening...

Bringing together students' views expressed in the questionnaire and in the thinking journals, it seems clear that students held even more positive views towards the second MT project than the initial MT in EFL Reading. In both projects (especially in 
the second MT project), students also reported that their conscious awareness of EFL learning had been enhanced. Given the complexities of the notion of learner autonomy, it is still hard to measure whether our learners have actually become more autonomous through MT. Actually, measuring the development of autonomy is a very complex and challenging issue that extends beyond the scope of this paper (for more discussion on measuring autonomy, see Benson, 2001, pp. 51-54). However, students’ generally positive views towards the two MT projects suggest that the incorporation of MT into the regular EFL curriculum is a worthwhile classroom activity which has a great potential for the development of autonomy in EFL learning.

\section{More Critical Reflections}

This paper explores students' attitudes towards MT in the Chinese EFL classroom. Generally speaking, students held positive views towards MT incorporated into the regular EFL curriculum (e.g. EFL Reading and Language Teaching Methodology). However, the study has also identified concerns that merit further exploration as well as areas of MT that need improvement:

First, in both projects, about $60-70 \%$ of the students stated that they were not interested in keeping a learning journal although a similar percentage of them recognized the value of learning journals as a tool to raise conscious awareness of learning. This seemed to illustrate two important points: first, learning journals demand careful planning and informed administration to ensure the benefits often claimed in the EFL literature (e.g. as a learning tool for reflection and self-evaluation; 
see Bailey \& Nunan, 1996; Matsumoto, 1996; Goh, 1997); second, teachers need not be too disappointed about learners' lack of interest in journal-writing as long as learners have recognized the value of journal-writing. This latter point boils down to the issue of learner motivation - that is, the teacher might need to find ways to motivate learners to write. In the current study, journals were treated as some form of continuous assessment on the grounds that course requirements might be the most effective way available to motivate (force) students to write to reflect. It proved 'effective’ in involving students in writing the journals through the exercise of teacher power, but failed to nurture students' interest in writing journals for its own sake (using journals as a reflective tool). In addition, the quantitative and qualitative criteria used to grade journals were also problematic. Students might try to satisfy first ‘quantity’ by writing superficially, knowing that ‘quality’ was a matter largely beyond the teacher's control, due to the large number of diary entries produced by more than 100 students (which was a real problem when I marked the journals!). In summary, this kind of external force could result in extrinsic motivation but not intrinsic motivation because students might regard this controlling activity as being antagonistic to their personal autonomy (Deci \& Flaste, 1995). In retrospect, if I had negotiated with students to come up with a certain kind of choice for the continuous course assessment, if I had listened and responded promptly to their voices expressed in their on-going entries (e.g. their learning difficulties and immediate concerns), and if I had taken journal-writing as an opportunity to engage students in regular teacher-learner dialogue and to share with them the power that was mostly in my 
hands, their motivation towards journal-writing (and perhaps autonomy in general learning) would have been enhanced.

Secondly, I observed learner resistance to MT in EFL Reading due to a certain mismatch between my expectations (metacognitive knowledge of the reading/learning process) and those of the students (good TEM-4 performance). This suggests that pro-autonomy teachers should negotiate classroom role relationships and mediate classroom methodologies, with learners, within the existing constraints of the actual socio-educational context. In so doing, we might provide students with autonomy support - 'taking their perspective and seeing the world from their point of view' (Deci \& Flaste, 1995, p. 100). However, in the case of MT in EFL Reading, should the teacher take the position as a helper of examinations, or a facilitator of metacognitive and reflective learning process? Based on my many years’ observation of the Chinese EFL classroom, if the teacher distances himself/herself from students' influential examinations in order to adopt a predominantly process-oriented approach to teaching, he/she will run the risk of doing a disservice to students from students' perspectives, and will thus make him/her unpopular with students. On the other hand, if the teacher serves only as a guarantor of examination success, he/she will contribute little to our ultimate educational goal (e.g. learner autonomy). As such, much in-depth classroom research is needed to strike an optimal balance between a focus on the learning process and a pragmatic expectation of the quick learning product, in an examination-oriented context.

Thirdly, based on the ineffective teaching procedures adopted in the second 
MT project (e.g. not providing sufficient opportunities to illustrate and reinforce strategy use, and using difficult instructional materials), I have come to realize that knowledge of learning strategies gained in the classroom should be reinforced by opportunities to practise in real-life experience over a sufficiently long period of time. In addition, it should be the teacher's responsibility to make the training content more accessible to learners to ensure greater benefits from learner training.

The limitations and uncertainties discussed above could help us gain a better understanding of the complex nature of learner training in the Chinese EFL classroom. In addition, this action research study has provided us with other practical insights about conducting learner training in the future. For example, in comparing the two MT projects, the data shows that the second MT project was more successful (e.g. ample positive comments in the open-ended questionnaire responses and in thinking journals). Probable reasons included:

- There was a secondary focus on the explicit instruction of cognitive and social/affective strategies in addition to a primary focus on metacognitive strategies. Students thus found 'strategies' to be less abstract and more relevant to their own learning experience.

- Students in the third year of the four-year BA TEFL programme had much less examination pressure. This might enable them to focus more on the process rather than the product of learning.

- Student teachers were then also learning how to teach. Their conceptualizations of 
their own future roles as primary and secondary school teachers contributed to their motivation for LLS.

- The teacher/trainer became relatively more informed and experienced in conducting MT.

- At least some of the students had gained some insights from the initial MT in EFL Reading prior to the second MT project (see Footnote 5).

From the above five points, we might suggest, though tentatively, that the following factors are important to the success of learner training (e.g. MT): the inclusion of different categories of LLS in a training programme; learner motivation and expectations embedded in a certain learning context; learners' perceptions of their future roles; teachers' expertise in learner training; and perhaps, students' previous experience in learner training.

\section{Concluding Remarks}

This action research study was guided by the assumption that learner autonomy could be fostered through enhancing metacognitive awareness (knowledge) of the learning process. However, from my experience in conducting the two MT projects, I have come to realize that learner training (e.g. through raising learners' metacognitive knowledge) will contribute little to the actual development of learner autonomy, if learner training is not supported by the genuine negotiation of the curriculum and classroom methodologies and the necessary accommodation of students' immediate 
concerns (in our case, examination performance and more visible improvement in language skills). In the current action research study, I was so preoccupied with finding solutions to the problems identified by myself that I was unable to gain sufficient understanding of the learning situation (e.g. reasons hidden behind the problems) before I took actions for improvement and change. That was probably a reason why my intervention for change was confronted with a degree of learner resistance (and therefore its potential benefits to learners might have been somewhat undermined). This is a valuable insight emerging from the current study and future action research should take this into consideration.

In terms of my professional development, I would like to assert that in the course of action research, I have developed my own autonomy as a teacher, which will help the development of learner autonomy. Being aware that the development of learner autonomy was not simply a matter of raising students' metacognitive awareness of learning process (the technical and psychological dimensions of learning), in my later teaching that followed the action research project, I have been taking efforts to understand also the socio-educational and political dimensions of learning and have gradually learned how to make informed choices within the given social and institutional constraints.

\section{Acknowledgements}

I am grateful to Desmond Allison, Phil Benson and Geoff Smith for their insightful comments on the earlier versions of this article. Thanks also go to Bridget Somekh, Jean Davidson and the two anonymous reviewers for their constructive feedback and help in the revision of this paper. 


\section{Correspondence}

HUANG Jing, English Centre, University of Hong Kong, Pokfulam Road, Hong Kong (peterjh@hkusua.hku.hk).

\section{References}

Bailey, K.M. \& Nunan, D. (Eds) (1996) Voices from the Language Classroom: qualitative research in second language classroom. Cambridge: Cambridge University Press.

Benson, P. (1995) A Critical View of Learner Training, Learning Learning: JALT Learner Development $N$-SIG Forum, 2(2), pp. 2-6.

Benson, P. (2001) Teaching and Researching Autonomy in Language Learning. Harlow, England: Pearson Education.

Block, E. L. (1992) See How They Read: comprehension monitoring of L1 and L2 readers, TESOL Quarterly, 26, pp. 319-343.

Brown, H.D. (1994) Teaching by Principles: an interactive approach to language pedagogy. Englewood Cliffs, N.J.: Prentice Hall Regents.

Casanave, C.P. (1988) Comprehension Monitoring in ESL Reading: a neglected essential, TESOL Quarterly, 22, pp. 283-302.

China Ministry of Education. (2001) English Curriculum Criteria for Full-time Compulsory Normal Middle Schools in China (trial version), Foreign Language Teaching and Research in Basic Education (Journal of National Basic Foreign Language Teaching Research Centre, China), 4, pp. 7-24.

Cohen, A.D. (1998) Strategies in Learning and Using a Second Language. Harlow, England: Longman.

Deci, E.L. \& Flaste, R. (1995) Why We Do What We Do: the dynamics of personal autonomy. New York: G. P. Putnam's Sons.

Dickinson, L. (1992) Learner Autonomy 2: learner training for language learning. Dublin: Authentik.

Ellis, R. (1994) The Study of Second Language Acquisition. Oxford: Oxford University Press.

Goh, C. (1997) Metacognitive Awareness and Second Language Listeners, ELT Journal, 51, pp. 361-369.

Hedge, T. (2000) Teaching and Learning in the Language Classroom. Oxford: Oxford University Press.

Irwin, J.W. (1991) Teaching Reading Comprehension Processes. New Jersey: Prentice-Hall.

Mariani, L. (1997) Teacher Support and Teacher Challenge in Promoting Learner Autonomy, Perspectives, 23(2). Available at: http://utenti.tripod.it/learning_paths/Mypapers/Papersupport.htm.

Matsumoto, K. (1996) Helping L2 Learners Reflect on Classroom Learning, ELT Journal, 50, pp. 143-149.

McDonough, S.H. (1999) Learner Strategies (state-of-the-art review), Language Teaching, 32, pp. $1-18$.

O’Malley, J.M. \& Chamot, A.U. (1990) Learning Strategies in Second Language Acquisition. Cambridge: Cambridge University Press.

Oxford, R.L. (1990) Language Learning Strategies: what every teacher should know. New York: Newbury House.

Rees-Miller, J. (1993) A Critical Appraisal of Learner Training: theoretical bases and teaching implications, TESOL Quarterly, 27, pp. 679-689.

Rubin, J. (1975) What the ‘Good Language Learner’ Can Tell Us, TESOL Quarterly, 9, pp. 41-51. 
Schmenk, B. (2005) Globalizing Learner Autonomy, TESOL Quarterly, 39, pp. 107-118.

Sinclair, B. \& Ellis, G. (1992) Survey: learner training in EFL course books. ELT Journal, 46, pp. 209-225.

Stern, H.H. (1975) What Can We Learn from the Good Language Learners? Canadian Modern Language Review, 31, pp. 304-318.

Wang, S.R. \& Yao, Y. (Eds) (1996) A Sophomore English Reader (III). Shanghai: Shanghai Foreign Languages Education Press.

Wen, Q.F. (1996) English Learning Strategies. Shanghai: Shanghai Foreign Languages Education Press.

Wenden, A. (1991) Learner Strategies for Learner Autonomy. Hemel Hempstead: Prentice Hall.

Wenden, A. (1995) Learner Training in Context: a knowledge-based approach, System, 23, pp. 183-194.

Wenden, A.L. (1998) Metacognitive Knowledge and Language Learning, Applied Linguistics, 19, pp. 515-537.

Williams, M. \& Burden, R.L. (1997) Psychology for Language Teachers. Cambridge: Cambridge University Press.

Zhang, L.J. (2003) Research into Chinese EFL Learner Strategies: methods, findings and instructional issues, RELC Journal, 34, pp. 284-322.

Appendix 1 (yield $=92$, out of 104 respondents in 3 classes)

Please circle the score that best summarizes your reaction to each statement (1=Strongly disagree, 2=Disagree, 3=Uncertain, 4=Agree, 5=Strongly agree) (figures in parentheses indicating the combined percentages of “Agree” and “Strongly Agree”):

1. The whole-class discussion about successful reading strategies used by different students has been useful to improve my reading ability. $12345 \quad \mathbf{( 6 8 \% )}$

2. The teacher's explicit explanation of reading processes in class has been effective to improve my reading comprehension. $12345 \quad \mathbf{( 7 0 \% )}$

3. When reading comprehension broke down in class, the teacher's incidental teaching of reading processes using specific paragraphs and contexts has helped me clarify the source of my comprehension problems. 12345 (83\%)

4. Keeping a reading diary has been useful and effective in raising consciousness of my reading processes. 12345 (59\%)

5. Reflecting on my own reading processes (sharing information) in a small group in class has helped me become aware of my strengths and weaknesses in reading and thus enhance my reading comprehension. 12345 (83\%)

6. In class, the teacher often helped students analyze how they actually arrived at a correct/wrong answer by means of asking them to recall their processes in understanding a certain question. I think that this has been useful to improve my reading comprehension. 12345 (79\%)

Please tick the statement that best fits you (figures in parentheses indicating results of analysis):

7A. _ I have been interested in writing reading diaries throughout this course. (30\%)

7B. __ I have not been interested in writing reading diaries throughout this course. (70\%) 
Appendix 2 (yield $=109$ out of 111 respondents in 3 classes)

Part One: Please indicate how much you agree or disagree with each of these statements by circling the number which matches your answer (1=strongly disagree; 2=disagree; 3=undecided; 4=agree; $5=$ strongly agree) (figures in parentheses indicating the combined percentages of "Agree" and “Strongly Agree”).

1 It is important to include the component of language learning strategies in our Language Teaching Methodology course. 12345 (95\%)

2 I think that metacognitive knowledge/strategies should be an important part of our learning strategies training programme. $12345 \quad \mathbf{( 8 7 \% )}$

3 The learning strategies component has helped me reflect on my own language learning experience and language learning process. $12345 \quad \mathbf{( 7 6 \% )}$

4 The learning strategies component has helped me understand my own language learning strategies and process. $12345 \quad \mathbf{( 8 2 \% )}$

5 The learning strategies component has helped me use language learning strategies more effectively than before. $12345 \quad \mathbf{( 5 4 \% )}$

6 The learning strategies component has helped improve my language performance, for example, in listening, reading, speaking and writing. $12345 \quad \mathbf{( 5 9 \% )}$

7 The learning strategies component will continue to benefit my language learning in the future. 12 345 (81\%)

8 I believe that the knowledge and strategies I have learned from the learning strategies component will help me solve learning problems in other non-language subjects. $12345 \quad \mathbf{( 4 9 \% )}$

$9 \quad$ I have become more responsible for my own language learning. 12345 (63\%)

10 I have become more confident in my language learning. $12345 \quad$ (46\%)

11 Keeping a thinking journal has helped me reflect on my own learning experience. 12345 $(68 \%)$

12 I have become more interested in keeping a thinking journal. $12345 \quad$ (39\%)

13 Writing papers on learning strategies has proved useful for me to understand my language learning strategies and process. $12345 \quad \mathbf{( 7 5 \% )}$

14 I will conduct some sort of learning strategy training with my own students when I become a teacher. 12345 (90\%)

15 If I conduct some sort of learning strategy training with my own students, I will include metacognitive knowledge/strategies as an important part of the training program. 12345 (67\%)

Part Two

Please give comments on the possible impact of the language learning strategies package on your EFL learning. What do you think of the way strategy training has been conducted in our classroom? 